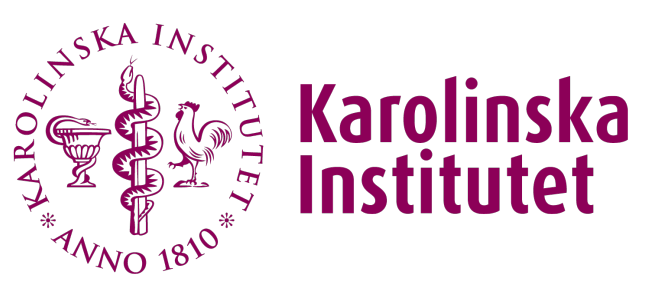

Karolinska Institutet

http://openarchive.ki.se

This is a Peer Reviewed Accepted version of the following article, accepted for publication in Health and Place.

\title{
Regional differences in health status in \\ China : population health-related \\ quality of life results from the National \\ Health Services Survey 2008
}

Sun, Sun; Chen, Jiaying; Johannesson, Magnus; Kind, Paul; Xu, Ling; Zhang, Yaoguang;

Burström, Kristina

Health Place. 2011 Mar;17(2):671-80.

Elsevier

http://doi.org/10.1016/j.healthplace.2011.01.007

http://hdl.handle.net/10616/40784

If not otherwise stated by the Publisher's Terms and conditions, the manuscript is deposited under the terms of the Creative Commons Attribution-NonCommercial-NoDerivatives License (http://creativecommons.org/licenses/by-nc-nd/4.0/), which permits non-commercial re-use, distribution, and reproduction in any medium, provided the original work is properly cited, and is not altered, transformed, or built upon in any way. 


\section{sines seth 4 ${ }^{1 / N}$ O $181^{\circ}$ \\ Karolinska Institutet}

This is an author produced version of a paper published in

\section{Health \& Place}

This paper has been peer-reviewed but does not include the final publisher proof-corrections or journal pagination.

Citation for the published paper:

Sun S, Chen J, Johannesson M, Kind P, Xu L, Zhang Y, Burström K., "Regional differences in health status in China: population health-related quality of life results from the National Health Services Survey 2008"

Health \& Place 2011 Mar;17(2):671-80. Epub 2011 Jan 28.

URL: http://dx.doi.org/10.1016/j.healthplace.2011.01.007

Access to the published version may require subscription. 
Regional differences in health status in China: Population health-related quality of life results from the National Health Services Survey 2008

\section{Word account}

Abstract: 889 characters with space, 132 words

Text (including abstract, key words, references and acknowledgement): 6,574 words Number of tables: 8

Number of figures: 1 


\begin{abstract}
Purpose: to measure, describe and analyse regional differences in health-related quality of life measured by EQ-5D in China. Data were obtained via face-to-face interviews on a national representative sample $(n=120,703,15-103$ years). The EQ-5D instrument was used to measure health status. Results: Rural areas had worse health status than urban areas. Health status was worst in western areas and best in eastern areas, and such disparities were profounder in rural areas. In urban areas, health status was best in middle-sized cities. In rural areas, health status increased with the economic development level of a county. Conclusion: Our study enhances understanding of the urban-rural differences and east-middle-west differences in health and sheds light on inequalities in health status between different city categories in the urban areas and county categories in the rural areas.
\end{abstract}

\title{
Key words
}

China; EQ-5D; regional health inequalities; rural population; urban population 


\section{Introduction}

Disparities in population health exists not only between countries (König, Bernert, Angermeyer, Mattschinger, Martinez, \& Vilagut, 2009; Szende \& Williams, 2004) but also within a country. Compared to developed countries (Bellanger \& Jourdain, 2004; Burström et al., 2010; LopezCasasnovas, Costa-Font, \& Planas, 2005; Salmela, 1993) such disparities are more serious in developing countries (World Health Organization [WHO], 2001). Ranking by equality in health distribution from high to low, China came 101st out of 191 member states of WHO.

Many factors contributes to regional differences, e.g. natural conditions, socio-economic development, health resource allocation etc. (Bellanger \& Jourdain, 2004; Burström et al., 2010; Fang, Dong, Xiao, \& Liu, 2009; Lopez-Casasnovas et al., 2005). China is a heterogeneous country, with 1.3 billion inhabitants distributed over 9.6 million $\mathrm{km}^{2}$ of territory (Central People's Government of the People's Republic of China [CPGPRC], 2004). Regional differences in China present a complex picture, with different types and levels (United Nations Development Programme [UNDP], 2005; Pei \& Rodriguez, 2006). There are three large geographic areas in China: the eastern, middle and western areas. Each of those areas contains about 10 provinces, in total 31 provinces in mainland China (CPGPRC, 2004). Under each province, there are cities in urban areas and counties in rural areas, on average 70 cities/counties per province. About $70 \%$ of the Chinese population live in rural areas and the majority live by agriculture. Regional disparities exist not only between urban and rural areas, but also between east, middle and west and between different cities (urban) and counties (rural).

The regional disparities existing historically have been widening rapidly since the economic reform of the 1980s (Office of WHO Representative in China and Social Development Department of China State Council Development Research Center [OWHORC \& SDDCSCDRC], 2006; UNDP, 2005). The rapid economic growth and dramatic social and political system transition have assumed different magnitudes in different regions, being more 
thorough and deeper in the east and urban areas (OWHORC \& SDDCSCDRC, 2006; UNDP, 2005). This has impacted heavily on health: overall, the Chinese are living longer and are healthier (OWHORC \& SDDCSCDRC, 2006), but at the same time, disparities in health between different regions are widening, e.g. large gaps in life expectancy between urban and rural (75.2 compared to 69.6 years), eastern and western areas (71.9 compared to 68.4 years) (UNDP, 2005). The recent health care reform makes reduction of regional inequalities in health a priority field (National Development and Reform Commission [NDRC], 2009). Large studies of inequalities in health in China have focused on the urban-rural issues (Liu, Hsiao \& Eggleston, 1999; Shi, 1993; Tang, Meng, Chen, Bekedam, Evans, \& Whitehead, 2008), but there is a shortage of studies regarding eastern-middle-western areas (UNDP, 2005), and differences between different types of cities and counties. A recent study revealed that there are distinct disparities in mortality and morbidity across different provinces in China (Fang et al., 2009).

China has substantial regional differences in health care systems (Shi, 1993) and insurance schemes (Xu, Wang, Collins, \& Tang, 2007), which has attracted attention in recent years (Gao, Qian, Tang, Eriksson, \& Blas, 2002; Shi, 1993; Henderson, Akin, Li, Jin, Ma, \& Ge, 1994). Regional differences in socio-economic developments and health resource allocation have been considered common factors leading to inequalities in health (Bellanger \& Jourdain, 2004; LopezCasasnovas et al., 2005; Salmela, 1993), and have been investigated in China as well (Henderson et al., 1994; Fang et al., 2009; Pei \& Rodriguez, 2006; UNDP, 2005).

Studies of regional inequalities in health mostly used mortality and morbidity measures (Gao et al., 2002; Fang et al., 2009), as well as the usage of health service (Henderson et al., 1994); there are few studies using health-related quality of life (HRQoL) measures in China. HRQoL reflects multi-dimensions of health, such as physical, psychological, social, cognitive and role function, as well as general wellbeing (Spiker \& Revicki, 1996). Outcome measures 
which neglect impacts on HRQoL might tend to underestimate the health disadvantage of deprived areas (Congdon, 2001).

The EQ-5D instrument has been used worldwide to measure HRQoL (Rabin \& de Charro, 2001). EQ-5D population health studies have been performed mostly in Europe (Burström, Johannesson, \& Diderichsen, 2001; Kind, Dolan, Gudex, \& Williams, 1998; König et al., 2009; Sorensen, Davidsen, Gudex, Pedersen, \& Bronnum-Hansen, 2009; Szende \& Williams, 2004), USA (Fryback, Dunham, Palta, Hanmer, Buechner, \& Cherepanov, 2007; Lubetkin, Jia, Franks, \& Gold, 2005; Luo, Johnson, Shaw, Feeny, \& Coons, 2005), Canada (Leung, Luo, So, \& Quan, 2007) and Asia (Kil, Lee, Yun, An, \& Jo, 2008; Shafie, Hassali, \& Liau, 2010; Ting, Tarn, Ching, Liou, Shaw, \& Chiou, 2007; Tsuchiya, \& et al., 2002), including China (Sun et al., 2010; Wang, David, Mullahy, \& Mullahy, 2005). Studies among other Chinese populations have also been performed in Singapore (Luo, Chew, Fong, Koh, Ng, \& Yoon, 2003), the USA (Lubetkin et al., 2007; Luo et al., 2005) and Canada (Leung et al., 2007). Results from an EQ-5D study performed in Beijing suggested that EQ-5D is valid for measuring health status in the Chinese population (Wang et al., 2005).

The EQ-5D was included for the first time in the National Health Service Survey (NHSS) 2008 to measure population health status in all 31 provinces in mainland China (Sun et al., 2010). In the present study, we investigated regional inequalities in HRQoL on a national representative sample from four different levels: urban-rural differences, eastern-middle-western differences, inter-city differences and inter-county differences.

\section{Aim}

To measure, describe and analyse regional differences in HRQoL measured by EQ-5D in China. 


\section{Material and Methods}

\section{Material}

Data were derived from the NHSS 2008, which has been organised by the Ministry of Health (MoH) in China every fifth year since 1993 (Center for Health Statistics and Information of Ministry of Health of People's Republic of China [CHSIMOHPRC], 2009). Face-to-face interviews were conducted by trained local interviewers (Center for Health Statistics and Information of Ministry of Health of People's Republic of China [CHSIMOHPRC], 2008). The NHSS 2008 questionnaire includes more than 200 questions, on acute diseases and injuries, chronic and other diseases, hospitalisation, health-related behaviour, educational level, family income and employment status, social relations, safety and security, medical care fees, accessibility (distance and time) and satisfaction with health service, insurance coverage, vaccination and disease control, woman and child health services. The EQ-5D was placed in the beginning of the questionnaire, after questions on general information and diseases and injuries, but before questions on health-related behaviour. The whole interview for each individual took generally around 45 minutes.

In NHSS 2008, 56,400 households were sampled using a multi-stage stratified cluster random sampling (CHSIMOHPRC, 2008). In the first sample stage, 2,400 districts (urban area) and counties (rural area) were stratified based on socio-economic, health care and population structure to sample 94 districts and counties. In the second stage, 2,350 sub-districts (Jiedao in Chinese) in urban area and townships (Xiang in Chinese) in rural area in the 94 counties were stratified based on population size and income per capita to sample 470 sub-districts and townships. In the third stage, 940 residential committees (Juweihui in Chinese) in urban area and villages (Cun in Chinese) in rural area were sampled using the same criteria as in the second stage. In each residential committee or village, 60 households were randomly selected, and all family members in a sampled household were interviewed individually. An oversampling of ten 
households in each residential committee (village) took place at the design stage, to make up for households that could not be reached (less than 7\%).

In total, 177,501 respondents were included in NHSS 2008. Of these, about $18 \%$ aged below 15 years were excluded, since EQ-5D questions should only be administered to respondents 15 years and over. Respondents not answering the questions by themselves were excluded (13\%). In total, less than $2 \%$ of the respondents had missing answers on age, sex, in at least one of the EQ-5D dimensions, on VAS or reported VAS higher than 100. After applying the previous exclusion criteria, 120,703 respondents were used for this study.

Ethical permission for analyses of this study was granted by the Regional Ethics Committee, Stockholm, Sweden (Dnr: 2009/1892-31).

\section{Interview procedure}

The interviewers were recruited from local health workers. The supervisors for interviewers were trained at the national level (4 supervisors per county, recruited from local health authority staff and county interviewers). The supervisors then trained the interviewers in each county (30 interviewers per county). An instruction for performing face-to-face interviews on NHSS questions was provided by MoH (CHSIMOHPRC, 2008). As a quality control, the supervisors checked the completeness of the questionnaire at the end of each day. If the information was missing, the interviewer went back during the same day or next day to ask the missing question again. If all family members in one household were missing, the interviewer would try to contact that family three times during the following days. If no family members were reached, the interviewer would choose another sampled household so as to clock up 60 households in each residential committee (village).

\section{Health outcome measure}

The EQ-5D instrument is a generic HRQoL outcome measure (Rabin \& de Charro, 2001) which classifies respondents' health status in five dimensions (mobility, self-care, usual activities, 
pain/discomfort and anxiety/depression), with three severity levels (no problems, some problems and severe problems). The EQ-5D instrument in total defines 243 health states.

A visual analogue scale (VAS) was used in the survey, with anchor points 0 (worst health state) and 100 (best health state). The scale consisted of a horizontal line where every $10^{\text {th }}$ was marked and labelled $0,10,20 \ldots, 100$. The question was framed: "On the scale please point out which point best represents your own health state today." The scale was harmonised to fit in with the NHSS questionnaire, and hence slightly differs from the EQ VAS. In the present study, the results are presented as VAS scores since they were not obtained with the original EQ VAS.

\section{Data analyses}

\section{Variables for region categorisations}

Variables for region categorisations in our study followed the official categorisations (CPGPRC, 2004; CHSIMOHPRC, 2009).

\section{Urban and rural areas}

Each province contains both urban and rural areas, on average 70 urban cities and rural counties (including county-level cities) per province. The under-provincial administrative tiers are presented in Figure 1. Below city (district) level in the urban areas, the administrative tiers from high to low are sub-districts (Jiedao in Chinese) and residential committees (Juweihui in Chinese); while below county level in rural areas, the administrative tiers are townships (Xiang in Chinese) and villages (Cun in Chinese).

Figure 1

\section{Eastern, middle and western areas}

The eastern area is alongside the sea coast, and is the most developed area. It includes 12 provinces: Liaoning, Beijing, Tianjin, Hebei, Shandong, Shanghai, Jiangsu, Zhejiang, Fujian, Guangdong and Hainan. Next to the eastern area is the middle area, including 9 provinces: 
Shanxi, Jilin, Heilongjiang, Anhui, Jiangxi, Henan, Hubei and Hunan. The western area is the least developed area, including 10 provinces: Sichuan, Chongqing, Guizhou, Yunnan, Tibet, Shaanxi, Gansu, Qinghai, Ningxia, Xinjiang, Guangxi and Inner-Mongolia.

\section{City and county categories}

In terms of administrative level and population size, the cities in urban areas can be divided into three categories: big, middle-sized and small cities. The big city category includes cities under the direct govern of the Central Government (Beijing, Tianjing, Shanghai and Chongqing) and province capital cities with a population of more than one million inhabitants. So-called prefecture cities, which are under the direct govern of the Provincial Governments, with a population of more than half million inhabitants and province capital cities with a population between half and one million inhabitants are in the middle-sized city category. Prefecture cities and provincial capital cities with a population less than half million inhabitants are in the small city category. The counties in the rural areas can be divided into four categories based on their socio-economic development level. Indicators such as economy, demography, literacy and health were used to define the socio-economic development level. The county categories are: Type I to Type IV (Type I is most developed and Type IV is least developed).

\section{Variables for socio-economic status}

The highest accomplished educational level was classified into below primary school; primary school; junior middle school; senior middle school; college and above. An individual's annual income was assessed by dividing household annual income by the numbers of persons living in the family within the last half-year, regardless of age and employment status. Respondents were then ranked from lowest to highest by their annual income and divided into five groups of equal size: the lowest income group had an income below 2,500 RMB; the second group from 2,500 to 3,999 RMB; the third group from 4,000 to 5,999 RMB; the fourth group from 6,000 to 9,9999 
RMB; the fifth group 10,000 RMB and above. Employment status was categorised into employed, unemployed, student and retired.

\section{Statistical analyses}

All descriptive analyses by region were stratified by sex and age groups (15-44 years; $45-64$ years; 65+). Percentages of respondents reporting problems in each EQ-5D dimension and VAS score (mean) were analysed by region. We carried out multiple logistic regression analyses to estimate the likelihood of having no problems in each of the EQ-5D dimensions. Multiple linear regression analysis was used to estimate the variation in VAS scores. We created two sets of models: in one set we controlled for sex and age (5-year age groups were entered as dummy variables, except for the oldest, 85+), and in the other set, we additionally controlled for educational level, income group and employment status (dummies entered based on the categorisation of socio-economic variables). Separate regressions were carried out for each region (urban-rural areas, eastern-middle-western areas, big-middle-small city categories and Type I-IV county categories), dummy variables were entered based on this regional categorisation. All analyses were performed in SAS 9.1 (SAS Institute). The significant level used in regression analyses was $5 \%$ level. 


\section{Results}

\section{Characteristics of respondents}

Characteristics of respondents by region are presented in Table 1. The proportion of women was higher in all regions, except in the rural Type IV county. In the rural area, there was a higher percentage of respondents with the lowest educational level (19\%) and in the lowest income group (29\%), compared to the urban area (7\% and 6\%, respectively.) The proportion of retired was low in the rural areas (2\%) compared to urban areas (32\%), and the employment rate was higher in the rural areas (82\%) than in the urban areas (41\%).

(Table 1)

\section{By urban and rural areas}

Rural respondents reported more problems in all the EQ-5D dimensions and lower VAS scores than the urban respondents (Table 2). The difference in problems reported in EQ-5D dimensions between the rural and urban respondents increased with age.

(Table 2)

\section{By eastern, middle and western areas}

Problems reported in EQ-5D dimensions increased and VAS scores decreased from eastern to western areas for both urban (Table 3) and rural respondents (Table 4). This gradient was steeper among rural than among urban respondents.

(Table 3 and 4) 


\section{By city category in urban areas}

For men aged 15-44 years, except for the anxiety/depression dimension, respondents from big city reported the lowest percentage of problems in all EQ-5D dimensions; for men aged 45 years and over, respondents from middle-sized cities reported the lowest problems in most EQ-5D dimensions (Table 5). For all age groups, men from small cities reported the highest percentage of problems in most EQ-5D dimensions.

For women aged 15-44 years, except for the usual activities dimension, respondents from middle-sized cities reported the lowest percentage of problems in all EQ-5D dimensions; for women aged 45-64 years, respondents from big cities reported the lowest problems in all EQ-5D dimensions. For women aged 65+, except for pain/discomfort and anxiety/depression dimensions, respondents from middle-sized cities reported the lowest percentage of problems in EQ-5D dimensions. For all the age groups, women from small cities reported the highest percentage of problems in most EQ-5D dimensions.

(Table 5)

\section{By county category in rural areas}

Overall, problems reported in EQ-5D dimensions increased and VAS scores decreased from Type I to Type IV county, most developed to least developed county, (Table 6). Exceptions were found for both men and women aged 15-44 years in the usual activities and pain/discomfort dimensions and men in mobility dimension, where Type II county respondents reported the lowest percentage of problems.

(Table 6) 


\section{Regression analyses}

For each region, the likelihood of having no problems in a specific EQ-5D dimension and the variation of VAS score were analysed, controlling for sex and age in Table 7, and also for educational level, income group and employment status in Table 8. The likelihood of women having no problems was significantly lower than for men, and women had significantly lower mean VAS scores than men. Individuals with a higher educational level, in a higher income group and gainfully employed were more likely to have no problems in EQ-5D dimensions, and they had higher mean VAS scores (results not shown).

In Table 7, when sex and age were controlled, rural respondents had significantly lower likelihood of having no problems in all EQ-5D dimensions and had significantly lower VAS scores than the urban respondents.

For urban areas, respondents in the eastern area were significantly more likely to have no problems in EQ-5D dimensions than those in the western area, with the exception of pain/discomfort. Difference in the anxiety/depression dimension was found between middle and western area respondents. Both eastern and middle area respondents had significantly higher VAS scores than western respondents. For rural areas, an eastern-middle-western gradient in health was observed; there were significant differences for all dimensions between all areas. In urban areas, overall, middle-sized city respondents had the best health, while the respondents in small cities had the worst. An exception was seen for VAS scores, where the lowest scores were found among big city respondents. In rural areas, a gradient in the likelihood to have no problems was seen for all EQ-5D dimensions and in the VAS score over Type I to Type IV county, i.e. respondents in Type IV county reported worst health.

(Table 7) 
In Table 8, after controlling also for socio-economic status, overall, the differences between regions were reduced and some differences became insignificant, but the trend was similar. This may suggest that the regional differences in health are partly due to differences in socio-economic composition between regions. Some exceptions were found for the rural easternmiddle-western areas, where the effects of regional variables increased in the dimensions selfcare, usual activities and anxiety/depression, after controlling for socio-economic status. The VAS score coefficient for the rural area became positive, which is the opposite of what can be seen in Table 7.

(Table 8) 


\section{Discussion}

We investigated regional inequalities in HRQoL measured by the EQ-5D instrument among the Chinese population stratified by sex and age from four different levels. Disparities in health between urban and rural areas have been demonstrated by previous studies (Gao et al., 2002; Henderson et al., 1994; Liu et al., 1999), and our study reported similar findings with the EQ-5D descriptive system, though with smaller differences. Respondents' health status decreased from eastern to western areas, which is in line with previous findings (Fang et al., 2009; Pei \& Rodriguez, 2007; UNDP, 2005). We also found such differences to be profounder in rural than in urban areas. In the urban areas, respondents from middle-sized cities reported best health; in rural areas, respondents' health status diminished from Type I to Type IV counties. To the best of our knowledge, this is the first time that regional inequalities in health have been investigated by applying the EQ-5D instrument to a nationally representative sample in China, and the intercity and inter-county differences in health have not yet been reported in any other articles published internationally.

Although the Chinese government has devoted much effort to reducing the huge disparities between urban and rural areas, e.g. by providing free education, building up the rural pension system, providing a new Rural Cooperative Medical System etc., the urban areas are still much more developed than the rural areas, e.g. the illiterate population is found mainly in rural areas (illiteracy rate: $4.6 \%$ in urban areas, $11.6 \%$ in rural areas) (UNDP, 2005), the number of persons with university education is higher and urban residents' per person income is higher. These differences will be profounder if all types of subsidies to urban respondents are taken into consideration (UNDP, 2005). China's urban-rural income inequalities might be the highest in the world (UNDP, 2005). The majority of rural respondents are employed in agriculture, and as peasants most of them do not have unemployment benefit or pension, and their social security network relies mainly on the family. 
We expected a large difference in health status between the urban and rural respondents, but as the results showed, although urban respondents reported better health than rural respondents, compared with studies based on life expectancy, mortality or morbidity data, the magnitude of the differences was smaller. In the regression analyses, when socio-economic status was controlled the opposite trend was found for VAS score. This might be linked with the way in which people judge their own health status. Studies suggested that respondents with lower expectation of health might rate their own health status higher (Sen, 2002; Symon, Daignault, Symon, Dunn, Sanda \& Sandler, 2006). The rural respondents might have a lower expectation of health than the urban respondents, in which case, given the same health conditions, the rural respondents might perceive their health status higher than the urban respondents. This issue needs further investigation.

The eastern-middle-western disparities in developments have existed historically. Although in recent years China's development strategy has more focused on western areas, e.g. low taxation and better transport conditions, national level fiscal transferring to the middle and western areas, encouraging people to migrate to western areas, there is still a huge gap between those areas. For example, the school drop-out rate is highest in the western area (UNDP, 2005), and average household income decreased from east to west.

From eastern area to western area, health status went from high to low, and disparities in health are profounder in rural than in urban areas. This might be due to that middle-sized cities being located mainly in the middle and west of China, and health is better in middle-sized cities. The possible reasons are given in the following paragraph, where we discuss about inter-city differences in health. In rural areas with the same socio-economic status, respondents' health status declined from eastern to western area.

Health status was best in middle-sized cities. The reason could possibly be that there is a lower stress level, better housing situation and a better environment in middle-sized cities than in 
big and small cities, but this issue needs further investigation (Van de Poel, O'Donnell \& Van Doorslaer). Big city respondents had fewer problems in EQ-5D dimensions than small city respondents. However, they had lower VAS scores, and this difference was enlarged after controlling for socio-economic status. Respondents in big cities might have higher expectations of health than small city respondents, and might rate their health lower for this reason (Sen, 2002; Symon et al., 2006).

Our results showed that from Type I to Type IV counties, health status went from high to low, and this gradient persisted when socio-economic status were all controlled. Type III and IV counties are mainly located in the mountain and desert region in the western area. Basic living conditions there are quite rough there, with respondents facing such problems as lack of clean drinking water and difficulties in communicating with the outside world, due to poor road conditions.

When interpreting the results, the minimum important differences (MID) in health status need to be addressed. To our best knowledge, there is no authoritative recommendation for the MID for EQ-5D. Some studies have investigated this issue, mainly focused on utility scores (Luo, Johnson \& Coons, 2010; Sullivan, Lawrence \& Ghushchyan, 2005; Walters \& Brazier, 2005). Most studies on MID for visual analogue scales are related to a certain health problem, e.g. pain or sleep problems (Salaffi, Stancati, Sivestri, Ciapetti \& Grassi, 2004; Zisapel \& Nir, 2002). Further studies are needed to explore this issue.

Some limitations must be addressed here, apart from limitations regarding how to define socio-economic status, interviewer bias and ceiling effects, which have been discussed elsewhere (Sun et al., 2010). The sampling design was complex, using a multi-stage sampling with both stratification and clustering. The difficulties of taking the effects of the sampling design into consideration at all stages of the analyses might affect the precision of our estimates. Nevertheless, the NHSS sampling design was examined by the MoH for all waves of the 
surveys, and the representativeness of the sample was considered good, i.e. proportions of the population from different regions, age, sex and socio-economic structures are representative of the Chinese population (CHSIMOHPRC, 2008), and are similar to the census data, except for the unemployment rate, which might be due to different ways of defining unemployment (National Bureau of Statistics of China, 2009).

Another limitation of our study is related to the situation concerning inner-immigrants, those rural respondents working in urban areas. This number has increased, and by 2002 will reach 150 million (UNDP, 2005). However, they were not included in our study. Innerimmigrants are often associated with low pay, harsh working and living conditions, and difficulties in accessing health care and social security networks, due to their not being registered residents of urban areas (Zhan, Sun, \& Blas, 2002). The NHSS question applied a proxy to investigate these persons' living situation, but information on their health status is lacking. Further studies are needed among the inner-immigrants.

There are large regional differences in income, and for the same amount of income the relative values are different in different regions, so that the income group could differ from one region to another. But in order to make cross-regional comparisons, we used the average income group for the whole country. The limitation of so doing is due to the fact that the same amount of money is worth more in poor regions.

Comparison of our results with population studies in other countries showed similar findings, with most problems reported in the pain/discomfort dimension, followed by the anxiety/depression dimension, more problems with increased age and women reporting worse health than men (Burström et al., 2001; Kind et al., 1998; König et al., 2009; Leung et al., 2007; Lubetkin et al., 2005; Sun et al., 2010; Sorensen et al., 2009; Szende \& Williams, 2004;). However, it is difficult to make a direct comparison for the proportion of respondents reporting problems in EQ-5D dimensions, as this differs from country to country. This might be due to 
several reasons other than the difference in health status between populations. The age and sex structure might be different across countries, or people in different countries might refer to levels of health differently (Szende \& Williams, 2004; Sorensen et al., 2009; Bharmal, \& Thomas, 2006), or again the mode of administration might vary from one survey to another (Bowling, 2005; Weinberger, Oddone, Samsa, \& Landsman, 1996), or some countries include proxy respondents. Therefore, one needs to be cautious when making international comparisons of population health status. A large ceiling effect (a large proportion of the population tending to report good health, which here refers to reporting no problems in any EQ-5D dimensions) as found in our study (87\%) has also been observed in other studies including Chinese populations, in China (Wang et al., 2005), as well as in US (Fu \& Kattan, 2006; Lubetkin et al., 2005) and Canada (Leung et al., 2007). This was also the case in a study in Japan (Tsuchiya et al., 2002) and in Malaysia (Shafie et al., 2010).

We have investigated different types of regional inequalities in health status, by using the EQ-5D instrument in a national representative sample. Given the caveats, the EQ-5D distinguished well between regions that were a priori supposed to differ in health status. Our study adds knowledge regarding regional disparities in different dimensions of health, apart from the known regional differences in health using mortality and morbidity data. This study enhances the understanding of the urban-rural differences and east-middle-west differences in China, and also sheds light on inequalities in health status between different city categories in the urban areas and county categories in the rural areas. The results can be used as EQ-5D norms data for different regions in China, and as a reference for further studies regarding regional health status. 


\section{Acknowledgement}

We would like to thank the Ministry of Health in China for data collection and their support of data analysis work. We acknowledge financial support from the Swedish Research Council (Swedish Research Links programme 348-2009-6538). We are also grateful for the helpful comments and suggestions received on earlier versions of this paper from the Equity and Health Policy Research Group, Department of Public Health Sciences, Karolinska Institutet, at the 26th EuroQol Plenary Meeting in Paris in 2009, at the 7th World Congress of Health Economics (iHEA) in Beijing in 2009, at the 16th Annual Conference of the International Society for Quality of Life Research (ISOQOL) in New Orleans in 2009, and from the Health Economics Research Group, Medical Management Centre, Karolinska Institutet. We would also like to thank two anonymous reviewers, for their constructive comments and valuable suggestions.

The EQ-5D is a copyrighted instrument and all requests for using it should be sent to the EuroQol Executive Office in Rotterdam, the Netherlands (userinformationservice@euroqol.org). 


\section{References}

Bellanger, M.M., \& Jourdain, A., 2004. Tackling regional health inequalities in France by resource allocation: a case for complementary instrumental and process-based approaches? Applied Health Economics and Health Policy, 3, 234-250.

Bowling, A, 2005. Mode of questionnaire administration can have serious effects on data quality. Journal of Public Health (Oxf) 27: 281-291.

Bharmal, M., \& Thomas, J., 2006. Comparing the EQ-5D and SF-6D descriptive systems to assess their ceiling effects in the US general population. Value in Health, 9(4), 262-271.

Burström, K., Johannesson, M., \& Diderichsen, F., 2001. Swedish population health-related quality of life results using the EQ-5D. Quality of Life Research, 10, 621-635.

Burström, B., Hemmingsson, T., Burström, K., Corman, D., Farah, A., Gustavsson, A., et al., (updated 21 May 2010). Livsvillkor, levnadsvanor och hälsa i Stockholms län: öppna jämförelser 2010. Living condition, living habits and health in Stockholm County: open comparison 2010. (In Swedish). Summary in English. Stockholm, Sweden: School of Public Health, Karolinska Institutet.

http://www.folkhalsoguiden.se/upload/folkh\%c3\%a4lsoarbete/Livsvillkor,\%20levnadsvanor \%20och\%20h\%c3\%a4lsa\%20i\%20Stockholms\%201\%c3\%a4n.pdf. Accessed 06.08.2010.

Centre for Health Statistics and Information of Ministry of Health of People's Republic of China., 2009. An analysis report of National Health Services Survey in China, 2008. (In Chinese).

Beijing, China: Centre for Health Statistics and Information of Ministry of Health of People's Republic of China.

Centre for Health Statistics and Information of Ministry of Health of People's Republic of China., 2008. The protocol and guidelines for the 4th National Health Service Survey. (In Chinese). Beijing, China: Centre for Health Statistics and Information of Ministry of Health of People's Republic of China.

Central People's Government of the People's Republic of China., 2004. Zhongguo de she hui bao zhang zhuang kuang he zheng ce. Situation and policy regarding China's social welfare. (In Chinese). Beijing, China: Central People's Government of the People's Republic of China.

Congdon, P., 2001. Health status and healthy life measures for population health need assessment: modelling variability and uncertainty. Health \& Place, 7, 13-25. 
Fang, P.Q., Dong, S.P., Xiao, J.J., \& Liu, C.J., 2009. Regional inequalities in health and its determinants: evidence from China. Health Policy, doi:10.1016/j.healthpol.2009.08.002.

Fryback, D.G., Dunham, N.C., Palta, M., Hanmer, J., Buechner, J., \& Cherepanov, D., 2007. US norms for six generic health-related quality of life indexes from the National Health Measurement Study. Medical Care, 45(12), 1162-1170.

Fu, A.Z., \& Kattan, M.W., 2006. Racial and ethnic differences in preference-based health status measure. Current Medical Research Opinion, 22(12), 2349-2348.

Gao, J., Qian, J.C., Tang, S.L., Eriksson, B., \& Blas, E., 2002. Health equity in transition from planned market economy in China. Health Policy Plan, 17, 20-29.

Henderson, G., Akin, J., Li, Z.M., Jin, S.G., Ma, H.J., \& Ge, K.Y., 1994. Equity and the utilization of health services: report of an eight-province survey in China. Social Science \& Medicine, 39(5), 687-699.

Hoi, L.V., Chuc, N.T.K., Lindholm, L., 2010. Health-related quality of life, and its determinants, among older people in rural Vietnam. BMC Public Health 10, 549.

Kil, S.R., Lee, S.I., Yun, S.C., An, H.M., \& Jo, M..W., 2008. The decline of health-related quality of life associated with some diseases in Korean adults. (In Korean). Journal of Preventive Medical Public Health, 41(6), 434-441

Kind, P., Dolan, P., Gudex, C., \& Williams, A., 1998. Variations in population health status: results from a United Kingdom national questionnaire survey. British Medical Journal, 316, 736-741.

König, H.H., Bernert, S., Angermeyer, M.C., Mattschinger, H., Martinez, M., \& Vilagut, G., 2009. Comparison of population health status in six European countries. Medical Care, 47(2), 255-261.

Leung, B., Luo, N., So, L., \& Quan, H., 2007. Comparing three measures of health status (perceived health with Likert-type scale, EQ-5D, and number of chronic condition) in Chinese and white Canadians. Medical Care, 45(7), 610-617.

Liu, Y., Hsiao, W.C., \& Eggleston, K., 1999. Equity and health care: the Chinese experience. Social Science \& Medicine, 49, 1349-1356.

Lopez-Casanovas, G., Costa-Font, J., \& Planas, I., 2005. Diversity and regional inequalities in the Spanish 'system of health care services'. Health Economics, 14, 221-235. 
Lubetkin, E.I., Jia, H.M., Franks, P., \& Gold, M.R., 2005. Relationship among sociodemographic factors, clinical conditions, and health-related quality of life: examining the EQ-5D in the U.S. general population. Quality of Life Research, 14, 2187-2196.

Luo, N., Chew, L.H., Fong, K.Y., Koh, D.R., Ng, S.C., \& Yoon, K.H., 2003. Validity and reliability of the EQ-5D self-report questionnaire in Chinese-speaking patients with rheumatic disease in Singapore. Journal of Rheumatol, 30(10), 2268-2274.

Luo, N., Johnson, J.A., Shaw, J.W., Feeny, D., \& Coons, S.J., 2005. Self-reported health status of the general adult U.S. population as assessed by the EQ-5D and Health Utility index. Medical Care, 43(11), 1078-1086.

Luo, N., Johnsson, J.A., \& Coons, S.J., 2010. Using instrument-defined Health State transition to estimate minimally important differences for four preference-based health-related quality of life instruments. Medical Care, 48, 365-371.

National Bureau of Statistics of China., (updated 2009). China Statistic Yearbook 2008. http://www.stats.gov.cn/tjsj/ndsj/2009/indexeh.htm. Accessed 24 August 2010.

National Development and Reform Commission., (updated 8 April 2009). Opinions of the China People's Congress Central Committee and State Council on Deepening the Health Care System Reform. http://www.china.org.cn/government/scio-press-conferences/200904/09/content_17575378.htm. Accessed 06.08.2010.

Office of the WHO representative in China and Social Development Department of China State Council Development Research Centre., (updated June 2006). China: health, poverty and economic development.

http://www.wpro.who.int/NR/rdonlyres/A1F18401-BE93-44EF-9F7655DDA2C6E12D/0/hped_en.pdf. Accessed 06.08.2010.

Pei, X., \& Rodriguez, E., 2006. Provincial income inequality and self-reported health status in China during 1991-7. Journal of Epidemiology Community Health, 60, 1065-1069.

Rabin, R., \& de Charro, F., 2001. EQ-5D: a measure of health status from the EuroQol Group. Annals of medicine, 33(5), 337-343.

Salaffi, F., Stancati, A., Silverstri, C.A., Ciapetti, A., \& Grassi, W., 2004. Minimal clinically important changes in chronic musculoskeletal pain intensity measured on a numerical rating scale. European Journal of Pain, 8, 283-291. 
Salmela, R., 1993. Regional inequalities in health and health care in Finland and Norway. Health Policy, 24, 83-94.

SAS Institute Inc., 2006. Base SAS® 9.1.3 Procedures Guide, Second Edition, Volumes 1, 2, 3, and 4. Cary, NC: SAS Institute Inc.

Sen, A. Health: perception versus observation: self reported morbidity has severe limitations and can be extremely misleading., 2002. British Medical Journal, 324, 860-861.

Shafie, A.A., Hassali, M.A., \& Liau, S.Y., 2010. A cross-sectional validation study of EQ-5D among the Malaysian adult population. Quality of Life Research, doi:10.1007/s11136-0109774-6.

Shi, L.Y., 1993. Health care in China: a rural-urban comparison after the socioeconomic reforms. Bulletin of the World Health Organization, 71(6), 723-736.

Sorensen, J., Davidsen, M., Gudex, C., Pedersen, K.M., \& Bronnum-Hansen, H., 2009. Danish EQ-5D population norms. Scandinavian Journal of Public Health, 37, 467-474.

Spiker, B., \& Revicki, D.A., 1996. Taxonomy of quality of life. In B., Spiker (Ed.), Quality of Life and pharmacoeconomics in clinical trials (pp.25-32). Philadelphia: Lippingcott-Raven Publishers.

Sun, S., Chen, J.Y., Johannesson, M., Kind, P., Xu, L., Zhang, Y.G., Burström, K., 2010. Population health status in China: EQ-5D results, by age, sex and socio-economic status, from the National Health Services Survey 2008. Quality of Life Research, doi:10.1007/s11136-010-9762-x.

Sullivan, P.W., Lawrence, W.F., \& Ghushchyan, V., 2005. A national catalogue of preferencebased scores for chronic conditions in the United States. Medical Care, 43, 736-749.

Symon, Z., Daignault, S., Symon, R., Dunn, R.L., Sanda, M.G. \& Sandler, H.M., 2006. Measuring patient's expectations regarding health-related quality-of-life outcomes associated with prostate cancer surgery or radiotherapy. Adult urology, 68, 1224-1229.

Szende A, \& Williams A (Eds.)., 2004. Measuring self-reported population health: an international perspective based on EQ-5D. Hungary: Spring Med Publishing Ltd.

Tang, S., Meng, Q., Chen, L., Bekedam, H., Evans, T., \& Whitehead, M., 2008. Tackling the challenges to health equity in China. Lancet, 372, 1493-1501. 
Ting, J.C., Tarn, Y.H., Ching, L.H., Liou, W.S., Shaw, J.W., Chiou, \& X.G., 2007. Taiwanese version of the EQ-5D: validation in a representative sample of the Taiwanese population. Journal Formosan Medical Association, 106(12), 1023-1031.

Tsuchiya, A., Ikeda, S., Ikegami, N., Nishimura, S., Sakai, I., Fukuda, T., et al., 2002. Estimating an EQ-5D population value set: the case of Japan. Health Economics, 11(4), 341-353.

United Nations Development Programme., (updated October 2005). China Human Development Report 2005: development with Equity.

http://ch.undp.org.cn/downloads/nhdr2005/c_NHDR2005_complete.pdf. Accessed 06.08.2010.

Van de Poel, E., O’Donnell, O., \& Van Doorslaer, E., 2009. Urbanization and the spread of diseases of affluence in China. Economics and Human Biology 7, 200-216.

Wang, H., David A., Mullahy K., \& Mullahy J., 2005. Variation in Chinese population health related quality of life: results from a EuroQol study in Beijing, China. Quality of Life Research, 14, 119-132.

Walters, S.J., \& Brazier, J.E., 2005. Comparison of the minimally important difference for two health state utility measures: EQ-5D and SF-6D. Quality of Life Research, 14, 1523-1532.

Weinberger, M., Oddone, E.Z., Samsa, G.P., \& Landsman, P.B, 1996. Are health-related quality of life measures affected by the mode of administration? Journal of Clinical Epidemiology, 49(2), 135-140.

World Health Organisation., (updated June 2001).The world health report 2000-Health systems: improving performance. http://www.who.int/whr/2000/en/whr00_en.pdf. Accessed 06.08.2010.

Xu, L., Wang, Y., Collins, D.C., \& Tang, S., 2007. Urban health insurance reform and coverage in China using data from National Health Services Surveys in 1998 and 2003. BMC Health Services Research, 2007, 7, 37. doi: 10. 1186/1472-6963-7-37.

Zhan, S.K., Sun, Z.W., \& Blas E., 2002. Economic transition and maternal health care for internal migrants in Shanghai, China. Health Policy Plan, 17, 47-55.

Zisapel, N., \& Nir, T., 2003. Determination of the minimal clinically significant difference on a patient visual analogue sleep quality scale. European Sleep Research Society 12, 291-298. 